\title{
O DESENVOLVIMENTO DA REGIÃO DO PONTAL DO PARANAPANEMA NO CONTEXTO DA REESTRUTURAÇÃO PRODUTIVA DO CAPITAL
}

\author{
THE DEVELOPMENT OF THE PONTAL DO PARANAPANEMA REGION IN THE CONTEXT OF \\ THE PRODUCTIVE CAPITAL RESTRUCTURING
}

Paulo Roberto Rosa *

\begin{abstract}
*Professor no IFSP - campus de Presidente Epitácio, e doutorando no PPG em Geografia UNESP/Campus Presidente Prudente - paulorosapp@hotmail.com.
\end{abstract}

Recebido em 08/03/2019. Aceito para publicação em 20/03/2019.

Versão online publicada em 26/04/2019 (http://seer.ufrgs.br/paraonde)

\begin{abstract}
Resumo:
Objetiva-se refletir sobre as contradições inerentes ao modo de produção capitalista e como a reestruturação produtiva impacta as políticas de desenvolvimento, postos de trabalho, distribuição de renda e qualidade de vida. Pretende-se ainda identificar alternativas para superar um modelo de desenvolvimento excludente, que prioriza o mercado em detrimento das pessoas. Foram realizadas pesquisas bibliográficas norteadas pelas temáticas centrais desenvolvimento e reestruturação produtiva. Parte-se do plano global para verificar como esse processo influencia as políticas de desenvolvimento e é determinante no avanço do setor sucroenergético no Pontal do Paranapanema. Uma aliança envolvendo o grande capital, latifundiários e o Estado possibilitou a territorialização e concentração do capital canavieiro, aumentando a complexidade da questão agrária na região ao possibilitar que o capital avance de forma predatória sobre os recursos disponíveis.
\end{abstract}

Palavras-chave: Desenvolvimento; Reestruturação produtiva; Sucroenergético.

\begin{abstract}
:
The goal of this work is to analyze the contradictions in the capitalist means o production and how the productive restructuration impacts the development policies, jobs, income distribution and quality of life. The intention is to identify alternatives to overcome and excluding development model, that gives priority to the market instead of the people. Bibliographical researches were made guided by the central thematic development and productive restructuration. Starting from the global plan to verify how this process influences the development policies and is determinant in the progress of the sugar and energy sector in Pontal do Paranapanema. An alliance involving great capital, farmers and state made possible the concentration of territory and capital from sugar cane production, enhancing the complexity of the Agrarian Issue in that region when it allows capital to progress in a predate way in the available resources.
\end{abstract}

Key-words: Development; Productive restructuration; Sugar and energy.

\section{Introdução}

O objetivo deste texto é refletir sobre as contradições presentes no modo de produção capitalista e como o processo de reestruturação produtiva impacta as políticas de desenvolvimento, postos de trabalho, distribuição de renda e qualidade de vida, maximizando a concentração de renda e ampliando o fosso que separa o reduzido número de pessoas extremamente ricas da massa empobrecida. Pretende-se identificar e apontar caminhos para superar o atual modelo de desenvolvimento - excludente, que prioriza o mercado em detrimento das pessoas -, rumo a uma sociedade mais justa e igualitária, centrada na pessoa humana. 
0 texto encontra-se organizado em três partes. A primeira apresenta uma aproximação caracterização da sociedade/modo de produção capitalista e do conceito de desenvolvimento. Na segunda parte é realizada uma discussão acerca da reestruturação produtiva e seus impactos sobre o mundo do trabalho. Na terceira parte realiza-se uma análise da Região do Pontal do Paranapanema e o papel historicamente por ela ocupado no contexto da reestruturação produtiva do capital.

\section{Desenvolvimento e modo de produção capitalista: uma breve aproximação conceitual}

As atuais relações sociais de produção são predominantemente capitalistas, hegemônicas, mas não únicas. Segundo Smith (1988, p. 130), "é a totalidade das relações espaciais organizadas, num grau maior ou menor dentro de padrões identificáveis, que adequadamente constituem a expressão da estrutura e do desenvolvimento do modo de produção". Amin (1976, p. 48) define "[...] o modo de produção capitalista a partir da apropriação exclusiva por uma classe dos meios de produção os quais são produto do trabalho social", sendo passível esta apropriação tanto na forma individual quanto coletiva. Para Hirsch $(1979$, p. 171), "o capitalismo de mercado nunca constitui a base exclusiva da economia política, em nenhum país e em nenhum momento".

As características básicas do modo de produção capitalista são definidas por Amin (1976, p. 48) como sendo: "1) a generalização da forma mercadoria a toda a produção social, 2) a aquisição da forma mercadoria à própria força do trabalho [...] e 3) a aquisição da forma mercadoria pelos equipamentos [...]; o que define o capital". Segundo Hirsch (1976, p. 173), "a economia capitalista compreende a organização da produção, acumulação e troca, por indivíduos privados, que operam isoladamente ou em grupos, e que agem livremente à base de contratos comerciais, motivados pelos lucros pecuniários", requerendo, para funcionar adequadamente, quatro tipos de capital: humano, financeiro, manufaturado e natural (HAWKEN; LOVINS; LOVINS, 2007).

Para Amin (1976, p. 51), "desde que o modo capitalista se tornou dominante, a forma dominante do excedente é o lucro do capital". A busca pelo lucro a qualquer preço, resultante das relações produção-consumo, constitui a essência do capitalismo. "Na busca do lucro, o capital corre o mundo inteiro. Ele coloca uma etiqueta de preço em qualquer coisa que ele vê [...]" (SMITH, 1988, p. 94). Quanto ao salário, Smith $(1988$, p. 86) assevera que "[...] é a medida do tempo de trabalho socialmente necessário para a reprodução do seu trabalho". Trata-se do "[...] tempo de trabalho necessário para produzir os objetos indispensáveis à manutenção contínua do trabalho, ou seja, para permitir que o trabalhador viva e propague a sua espécie" (MARX, 1985, p. 55). Resumindo, "o preço natural do trabalho é o mínimo do salário [...], a fórmula da escravidão moderna [...]" (MARX, 1985, p. 55-56).

Assim, "o valor da força de trabalho representa somente uma fração do exato valor produzido durante um dia de trabalho" (SMITH, 1988, p. 86). É da relação entre a força de trabalho requerida e da força de trabalho efetivamente remunerada que surge o conceito da mais-valia - ou mais-produto - estabelecido por Marx. A extensão da jornada de trabalho tem, assim, o papel determinante no nível de exploração, pois "quanto mais curto o dia de trabalho, menor a massa de mais-valia produzido sob a forma de lucro para a classe capitalista" (SMITH, 1988, p. 106).

Apesar da tendência geral apontada por Marx (1985) dos salários serem mantidos ao nível mínimo de subsistência e reprodução, a classe trabalhadora é totalmente dependente de vender a força de trabalho para sobreviver. Dessa forma, "a universalização da relação salário-trabalho pressagia ao trabalhador uma liberdade oferecida com uma mão - a liberdade de comprar e vender sua força de trabalho - mas tomada com a outra" (SMITH, 1988, p. 170).

A lógica do lucro que guia as opções do modo de desenvolvimento capitalista gerou desenvolvimento e subdesenvolvimento, concentrou a riqueza nas mãos de poucos, agravou as assimetrias entre continentes, países, regiões e cidades, dividindo-as entre poucos que tem e muitos que não tem. A desigualdade na distribuição e/ou acesso aos benefícios do desenvolvimento afeta as

Para0nde!?, Porto Alegre, v.11, n.1, p.01-08, 2019. http://seer.ufrgs.br/paraonde

Edição Especial: "Geografia e transformações socioespaciais: dinâmicas agrárias e políticas do desenvolvimento regional" 
relações e corrói, pouco a pouco, os vínculos sociais. A humanidade precisa encontrar o caminho para um modelo de desenvolvimento que permita romper com a ditadura da mercadoria imposta pelo modelo produtivista-consumista do capital, que solapa o tempo destinado ao lazer, à família e outras atividades não laborais; corrói laços sociais e a solidariedade, além de degradar e levar os recursos naturais à exaustão.

Considerado um fenômeno complexo e contraditório, o desenvolvimento "[...] é um reflexo das melhores aspirações humanas e, exatamente porque grandes ideias formam a base do poder, é objeto para a mais intensa manipulação e passível de ser usado para propósitos que invertem o seu ideal original" (PEET apud GIRARDI, 2016, p. 12, grifo do autor). 0 desenvolvimento deve ser considerado como um fenômeno amplo e multidimensional, contemplando as dimensões econômica, social, cultural, científica, tecnológica, ambiental, dentre outras.

A insuficiência explicativa e a insustentabilidade da dimensão econômica isolada no processo de desenvolvimento estão presentes nas análises de Rattner (1999), Sen (2010) e Girardi (2016), e apontam no sentido da necessidade de se romper com a tendência de algumas visões reducionistas em restringir o conceito do desenvolvimento ao âmbito do crescimento econômico. Rattner (1999, p. 23) aponta que "[...] o crescimento econômico não leva, necessariamente, à redução da pobreza, sobretudo quando combina uma distribuição flagrantemente desigual do produto social com o uso predatório e devastador dos recursos naturais". Em outras palavras, "[...] ele não coloca em questão e não tem como objetivo final a melhoria das condições gerais de vida da população e alguma forma mais incisiva de divisão da riqueza; ele é o objetivo final" (GIRARDI, 2016, p. 12).

Segundo Peet apud Girardi (2016, p. 12), as diferenças fundamentais entre desenvolvimento de crescimento econômico são as preocupações "[...] com as condições de produção [...] e as consequências sociais [...]". Além da redução da desigualdade e pobreza, o desenvolvimento só existe de fato quando permite às pessoas participarem do processo, ao amplia as liberdades existentes e/ou resultar em novos espaços de participação social, estando a liberdade no meio e no final do processo de desenvolvimento (RATTNER, 1999; SEN (2010). "A expansão da liberdade é vista, por essa abordagem, como o principal fim e o principal meio do desenvolvimento" (SEN, 2010, p. 10). 0 desafio imposto às políticas voltadas à promoção do desenvolvimento é romper as amarras impostas pelo grande capital e considerar o ser humano como elemento central e principal beneficiário.

\section{Reestruturação produtiva e rebatimentos sobre o trabalho}

As análises de Antunes (2009) indicam que o processo de reestruturação produtiva do capital tem início nos anos 1970. Trata-se de um processo global conduzido por grandes corporações transnacionais, envolvendo a distribuição dos recursos produtivos, investimentos, fluxos de comércio e transferências de tecnologia. $O$ objetivo é restituir o padrão de acumulação e a hegemonia perdida frente a resistência dos trabalhadores e as lutas sociais, através de condições mais favoráveis à produção e maximização da lucratividade, envolvendo a busca por territórios com ampla disponibilidade de recursos e onde a legislação de proteção social e dos recursos naturais inexista ou apresente possibilidade de flexibilização.

Autores como Amin (1976), Smith (1988), Chesnais (1996) e Santos (2005) analisaram o processo de globalização e mundialização do capital, bem como as empresas se posicionam e reposicionam ao redor do globo com o fulcro de explorar recursos e auferir o máximo de lucratividade ao menor custo. Amin (1976) e Smith (1988) apontam no sentido de que as empresas alocam suas atividades mais intensivas em trabalho, menos intensivas em capital e menos especializadas nos países subdesenvolvidos, retendo nos países desenvolvidos as atividades mais especializadas e intensivas em capital.

As análises realizadas por Rattner (1999) apontam que, por possuírem um poderio financeiro superior a muitos Bancos Centrais, inclusive de países desenvolvidos, as corporações transnacionais

Para0nde!?, Porto Alegre, v.11, n.1, p.01-08, 2019. http://seer.ufrgs.br/paraonde

Edição Especial: "Geografia e transformações socioespaciais: dinâmicas agrárias e políticas do desenvolvimento regional" 
controlam a economia mundial a ponto de influenciar decisivamente as políticas nacionais. As decisões relacionadas a reestruturação produtiva são tomadas pelas corporações transnacionais tendo como balizador principal a maximização do retorno sobre o investimento, ou seja, a rentabilidade (lucro) máxima, sem preocupação com os problemas ambientais e/ou as expectativas e necessidades da comunidade, em especial dos mais carentes.

Para Chesnais (1996, p. 17-18), "as operações feitas com finalidade lucrativa, para 'frutificar' um capital, são por definição [...] 'seletivas'. Não é todo o planeta que interessa ao capital, mas somente parte dele [...]". Isso acontece porque "[...] o capital recuperou a possibilidade de voltar a escolher, em total liberdade, quais países e camadas sociais que têm interesse para ele" (CHESNAIS, 1996, p. 18).

Com o processo de mundialização do capital, "abismo que separa os países participantes, mesmo que marginalmente, da dominação econômica e política do capital monetário rentista, daqueles que sofrem essa dominação, alargou-se ainda mais" (CHESNAIS, 1996, p. 18-19). A contradição desse processo é que o desenvolvimento acaba, com o passar do tempo, através da elevação da taxa de emprego, do nível salarial, da sindicalização, dentre outros, por "[...] baixar a taxa de lucro e a afastar a verdadeira razão para o desenvolvimento" (SMITH, 1998, p. 213). Smith (1998) destaca ainda que:

No polo oposto, o do subdesenvolvimento, a falta de capital ou seu constante excesso leva a altas taxas de desemprego, baixos salários e reduzidos níveis de organização dos trabalhadores. [...]. O subdesenvolvimento, como o desenvolvimento, ocorre em todas as escalas espaciais e o capital tenda se movimentar geograficamente de tal maneira que continuamente explora as oportunidades de desenvolvimento, sem sofrer os custos econômicos do subdesenvolvimento. Isto é, o capital tenta fazer um "vaivém" de uma área desenvolvida para uma área subdesenvolvida, para então, num certo momento posterior voltar à primeira área que agora se encontra subdesenvolvida, e assim sucessivamente (SMITH, 1998, p. 213).

0 trabalho e o contexto a ele relacionado desempenham um papel central na vida humana, sendo a realização do trabalho que, segundo Antunes (2009), distingue a forma de vida humana das demais formas de vida. Segundo Antunes (2009, p. 231, grifo do autor), "na longa história da atividade humana, em sua incessante luta pela sobrevivência, pela conquista da dignidade, humanidade e felicidade social, o mundo do trabalho tem sido vital". No entanto, o trabalho, sob o capitalismo, tem seu potencial emancipador sistematicamente corroído e sua finalidade deturpada, transformou-se "[...] em trabalho assalariado, alienado, fetichizado. 0 que era uma finalidade central do ser social converte-se em meio de subsistência (ANTUNES, 2009, p. 232, grifo do autor).

Não que o trabalho tenha perdido seu caráter edificante na constituição do ser humano, mas converteu-se numa necessidade para sobrevivência. As pessoas não escolhem mais as atividades que desejam realizar e tampouco as condições de sua realização. As atividades e condições são impostas pela empresa e aceitas pelo trabalhador sob o signo de que dali depende a sua sobrevivência e de sua prole. 0 processo de trabalho é contraditório, pois "[...] ao mesmo tempo cria e subordina, emancipa e aliena, humaniza e degrada, oferece autonomia, mas gera sujeição, libera e escraviza [...]" (ANTUNES, 2009, p. 233, grifo do autor). 0 principal beneficiário do trabalho deixa de ser o homem e passa a ser o capital. 0 processo de reestruturação produtiva traz novas e velhas formas de trabalho, todas formas de precarização do trabalho, modelos deturpados e ajustados aos interesses do capital.

Entender o caráter contraditório presente no contexto do trabalho sob o capital é fundamental para não cair nas armadilhas engendradas pelo discurso hegemônico, que busca demonstrar a inexistência de qualquer possibilidade fora do capital. "É no interior dessas contradições que se refaz cotidianamente a plasticidade das diferentes formas de expressão do trabalho humano" (THOMAZ JÚNIOR, 2004, p. 150). A construção de uma outra sociedade requer que se identifique as possibilidades de se construir as condições emancipatórias e as rupturas por dentro do atual sistema.

Para0nde!?, Porto Alegre, v.11, n.1, p.01-08, 2019. http://seer.ufrgs.br/paraonde

Edição Especial: “Geografia e transformações socioespaciais: dinâmicas agrárias e políticas do desenvolvimento regional” 


\section{A Região do Pontal do Paranapanema no contexto da reestruturação produtiva do capital}

A Região do Pontal do Paranapanema, localizada no extremo oeste do Estado de São Paulo, desde início do processo de ocupação, desempenha diversos papéis dentro do contexto produtivo, mas caracteriza-se, desde o princípio, por ser um empreendimento capitalista. As terras da região historicamente são utilizadas em monoculturas extensivas voltadas para exportação. A região já foi utilizada na produção de café, algodão, amendoim, pecuária e, atualmente, tem boa parte de suas terras comprometidas com a monocultura canavieira.

As análises de Leite (1981) e Monbeig (1984) demonstram que a ocupação da região é marcada pela estrutura fundiária altamente concentrada e disputas, conflitos e violência contra as pessoas. A histórica disputa por terras tem como origem um processo de ocupação desordenado, sem planejamento, baseado na propriedade da terra e no avanço do capital através da agricultura. A introdução de monoculturas, associadas a crescente mecanização, levou a drástica redução da demanda por mão de obra, provocando a migração da população camponesa para as áreas urbanizadas. No entanto, o baixo dinamismo industrial apresentado pela região concentrou nas cidades um excedente de mão de obra, favorecendo a exploração mediante condições desfavoráveis ao trabalho e baixos salários.

O setor sucroenergético chegou a Região do Pontal do Paranapanema em meados da década de 1970, através do Programa Nacional do Álcool - Proálcool - (BRAY, 1980; LEITE, 1981; BARRETO; THOMAZ JÚNIOR, 2012). Como parte de um pacote de 10 (dez) destilarias de álcool autônomas criadas através do Proálcool, é implantada no município de Teodoro Sampaio/SP a Destilaria Alcídia, a primeira da Região do Pontal do Paranapanema. Além desta, de acordo com Barreto e Thomaz Júnior (2012), na década de 1970 uma segunda unidade chega a região.

Na década de 1980 chegaram à região mais quatro unidades, aumentado para seis, todas de capital independente, ou seja, sem vínculo entre elas. 0 período compreendido entre meados da década de 1980 e o final da década de 1990 é protagonizado pelos movimentos sociais de luta pela terra, em busca de romper com o modelo latifundiário através da reforma agrária. A partir da década de 1990 o setor sucroenergético começa a de fato se consolidar na região e, com isso, a estrutura produtiva da região continua baseada no campo (LEITE, 1981; MONBEIG, 1984). No período compreendido entre 2005 e 2009 são implantadas na região mais quatro agroindústrias, atingindo o ápice de dez unidades industriais sucroenergéticas na região. É importante destacar esta etapa é marcada pela chegada de grupos empresariais de capital nacional e internacional, até então ausentes na região, com a incorporação de duas unidades que encontravam-se desativadas.

Trata-se de uma articulação do Estado que adota medidas complementares ao Proálcool tentando canalizar para a região a instalação de novas unidades sucroenergéticas e promover a integração econômica, o desenvolvimento e legaliza-ção fundiária (LEITE, 1981; RUAS; FERREIRA; SALES, 2014). São os subsídios governamentais que tem garantido a sobrevivência e monopólio do setor, deixando claro que é o capital, ao cooptar o Estado, quem direciona as políticas públicas para a agricultura, sendo a dependência dos subsídios, contraditoriamente, a maior vulnerabilidade apresentada pelo setor (BRAY, 1980; OLIVEIRA, 2010).

Como o capital não se interessa pela produção de alimentos, e sim pela produção de matérias primas para a indústria, os recursos para financiamento da atividade produtiva são claramente canalizados para atividades de interesse capitalista. As oscilações de mercado costumam afetar consideravelmente esse setor, gerando crises que são maximizadas pela dependência do setor com relação a financiamento - para não dizer subsídio ou empréstimos a fundo perdido - estatal, podendo culminar no fechamento de unidades.

Das dez unidades industriais sucroenergéticas que a região chegou a acumular, atualmente apenas cinco encontram-se em operação, uma está desativada temporariamente, três desativadas e

Para0nde!?, Porto Alegre, v.11, n.1, p.01-08, 2019. http://seer.ufrgs.br/paraonde

Edição Especial: "Geografia e transformações socioespaciais: dinâmicas agrárias e políticas do desenvolvimento regional" 
em processo de recuperação judicial, e uma encerrou definitivamente suas atividades, tendo a sua infraestrutura transferida para outra região do país. Isso demonstra que a região está passando por um processo de concentração do capital canavieiro. A territorialização do capital canavieiro aumentou a complexidade do histórico problema fundiário e da luta pela terra na região do Pontal do Paranapanema. "Nesse cenário, latifundiários/grileiros usam o período de crescimento do agronegócio canavieiro na região para justificar e obter a 'jurisprudência' das terras, e evitar que estas sejam designadas as políticas de Reforma Agrária" (BARRETO; THOMAZ JÚNIOR, 2012, p. 5).

A capacidade de monopolizar a produção da cana-de-açúcar e os produtos resultantes da industrialização decorre da aquisição ou arrendamento de terras. 0 poder dos usineiros, como integrantes da classe dominante, é utilizado para pressionar o governo, estabelecer o monopólio e impor formas precarizadas de trabalho, a exemplo dos trabalhos temporário e escravo (OLIVEIRA, 2010; IHU ON-LINE, 2011). Isso demonstra como o capital, ao cooptar Estado, atua de forma perniciosa no estabelecimento de políticas públicas que permitem explorar os recursos existentes, inclusive humanos, até a exaustão, com o objetivo de reduzir custos, aumentar a produtividade, maximizar a lucratividade, concentrar renda e propriedade, sem nenhuma responsabilidade com as consequências do processo.

\section{Considerações Finais}

O modo de produção capitalista não é recente e surge com a desagregação das relações feudais de produção, ou seja, ele é, ao mesmo tempo, a razão e o produto da desarticulação dessas relações. 0 Brasil não conheceu o feudalismo, pois sua colonização é um empreendimento capitalista. No entanto, amparado nas análises de Hirsch (1979), isso não significa que inexistam no Brasil relações não capitalistas de produção e que todas as relações de produção sejam capitalistas.

0 processo de reestruturação produtiva do capital a nível global leva o capital, transnacional e envolvendo grandes grupos industriais e financeiros, a avançar de forma predatória sobre os recursos disponíveis. Como afirma Rattner (1999, p. 97), "o capital não tem pátria e [...]", dado o grande poder econômico das corporações, irá exercer pressão sobre governos e instituições para obter as condições mais favoráveis à sua instalação e operação. Para isso, "[...] estimula-se e incentiva-se a concorrência ilimitada, a busca de aumento de produtividade, sem preocupação com as conseqüências sociais dessa corrida desenfreada [...] e seus efeitos destrutivos e poluidores do meio ambiente" (RATTNER, 1999, p. 34-35).

Para Smith (1988, p. 217), "[...] o capital é como uma praga de gafanhotos. Eles se estabelecem em um lugar, devoram-no e então se deslocam para praguejar outro lugar", exigindo das autoridades locais total isenção de responsabilidade quanto aos impactos diretos e indiretos por elas produzidos. Rattner (1999, p. 41) destaca que, "[...] como resultado da inovação tecnológica e das estratégias operacionais adotadas pelas corporações, um segmento crescente da população em todos os países vem se tornando desnecessário para o mercado de trabalho".

Como consequência do avanço capitalista, a sociabilidade é corroída e vários problemas de organização econômica e social são intensificados. Segundo Hirsch $(1979$, p. 121), "[...] o contato humano nas economias adiantadas é cada vez mais desejado, e cada vez menos conseguido". Para o autor, "é a ação individual para otimizar os objetivos individuais que é o problema" (HIRSCH, 1979, p. 122). 0 enfraquecimento da capacidade para estabelecer vínculos sociais acabou se tornando um fator limitante nas ações voltadas ao desenvolvimento.

São razões como essa que levam Rattner (1999, p. 55) a afirmar que "o maior desafio de nossa civilização urbano-industrial é como transformar uma estratégia de crescimento econômico direcionada contra a maioria pobre da população em um modelo de sustentabilidade baseado no bem-estar humano". Para Löwy (2011, p. 32, grifo do autor, tradução nossa), "uma reorganização do conjunto do modo de produção e de consumo é necessária, de acordo com critérios externos ao

Para0nde!?, Porto Alegre, v.11, n.1, p.01-08, 2019. http://seer.ufrgs.br/paraonde

Edição Especial: "Geografia e transformações socioespaciais: dinâmicas agrárias e políticas do desenvolvimento regional" 
mercado capitalista: as necessidades reais da população [...] e a proteção do meio ambiente".

Diante da realidade contemporânea, com uma sociedade altamente desigual, excludente e corrompida nos valores sociais, éticos, ambientais, etc.; tais pensamentos poderão ser considerados utópicos. Entretanto, Löwy (2011, p. 33) afirma que "a utopia é indispensável para a mudança social; extrai sua força das contradições da realidade e dos movimentos sociais reais". Segundo Löwy (2011), qualquer movimento que pretenda desafiar a ordem estabelecida deverá apresentar visões alternativas de mundo e da sociedade, apresentar um certo grau de utopia.

\section{Referências}

AMIN, Samir. 0 desenvolvimento desigual: ensaios sobre as formações sociais do capitalismo periférico. 1. ed. Rio de Janeiro: Forense, 1976.

ANTUNES, Ricardo. Século XXI: nova era da precarização estrutural do trabalho? In: ANTUNES, Ricardo; BRAGA, Ruy (Orgs.). Infoproletários: degradação real do trabalho virtual. São Paulo: Boitempo, 2009, p. 231-238.

BARRETO, Maria Joseli; THOMAZ JÚNIOR, Antonio. o cenário do agronegócio canavieiro na região do Pontal do Paranapanema-SP. XXI Encontro Nacional de Geografia Agrária. Uberlândia: UFU, 2012.

BRAY, Silvio C. A cultura da cana-de-açúcar no Vale do Paranapanema: um estudo da Geografia Agrária. 304 folhas. Tese (Doutorado em Geografia) - Faculdade de Filosofia, Letras e Ciências Humanas/USP - São Paulo, 1980.

CHESNAIS, François. A mundialização do capital. São Paulo: Xamã, 1996.

GIRARDI, Eduardo P. Relatório de pesquisa trienal - setor sucroalcooleiro paulista: importância econômica, internacionalização e impactos na questão agrária. Presidente Prudente: FCT/UNESP, 2016.

HAWKEN, Paul; LOVINS, Amory; LOVINS, L. Hunter. Capitalismo natural: criando a próxima revolução industrial. São Paulo: Cultrix, 2007.

HIRSCH, Fred. Limites sociais do crescimento. Rio de Janeiro: Zahar, 1979.

IHU On-Line. Trabalho escravo no Brasil: uma herança maldita do capitalismo - entrevista especial com Frei Xavier Plassat. São Leopoldo: Unisinos, 2011. Disponível em: <http://www.ihu.unisinos.br/entrevistas/41377-trabalho-escravo-no-brasil-uma-heranca-malditado-capitalismo-entrevista-especial-com-frei-xavier-plassat\%20\#>. Acesso em: 09 jan. 2017.

LEITE, José F. A ocupação do Pontal do Paranapanema. 256 folhas. Tese (Livre-Docência) Instituto de Planejamento e Estudos Ambientais da Universidade Estadual Paulista - Campus de Presidente Prudente, 1981.

LÖWY, Michael. Ecosocialismo: la alternativa radical a la catástrofe ecológica capitalista. Buenos Aires: El Colectivo - Herramienta, 2011.

MARX, Karl. A miséria da filosofia. São Paulo: Global, 1985.

MONBEIG, Pierre. Pioneiros e fazendeiros de São Paulo. São Paulo: Polis, 1984.

OLIVEIRA, Ariovaldo U. de. Agricultura e indústria no Brasil. Campo-Território: revista de geografia agrária, v. 5, n. 10, p. 5-64, Agosto de 2010.

RATTNER, Henrique. Liderança para uma sociedade sustentável. São Paulo: Nobel, 1999.

RUAS, Davi G. G.; FERREIRA, Enéas R.; SALES, Elias J. C. G. 0 deslocamento da agroindústria canavieira para o oeste do Estado de São Paulo. In: RUAS, Davi G. G.; FERREIRA, Enéas R.; BRAY,

Para0nde!?, Porto Alegre, v.11, n.1, p.01-08, 2019. http://seer.ufrgs.br/paraonde

Edição Especial: "Geografia e transformações socioespaciais: dinâmicas agrárias e políticas do desenvolvimento regional" 
Silvio C. (orgs.). A agroindústria sucroalcooleira nas áreas canavieiras de São Paulo e Paraná. Rio Claro: UNESP/IGCE, 2014, p. 191-211.

SANTOS, Milton. Por uma outra globalização: do pensamento único à consciência universal. 12. ed. Rio de Janeiro: Record, 2005.

SEN, Amartya. Desenvolvimento como liberdade. São Paulo: Cia. das Letras, 2010.

SMITH, Neil. Desenvolvimento desigual: natureza, capital e a produção do espaço. Rio de Janeiro: Bertrand, 1988.

THOMAZ JÚNIOR, Antonio. Se camponês, se operário ! Limites e desafios para a compreensão da classe trabalhadora no Brasil. In: THOMAZ JÚNIOR, Antonio (Org.). Geografia do trabalho no século XXI. V. 2. Pres. Prudente: Centelha, 2004, p. 135-170. 